\title{
ANALISE DA GESTÃO ESTRATÉGICA EM ORGANIZAÇÕES NÃO GOVERNAMENTAIS (ONGS) PERNAMBUCANAS POR MEIO DA PERSPECTIVA DO BALANCED SCORECARD
}

\author{
ANALYSIS OF STRATEGIC MANAGEMENT IN NON-GOVERNMENTAL \\ ORGANIZATIONS (NGOS) FROM PERNAMBUCO THROUGH THE \\ PERSPECTIVE OF THE BALANCED SCORECARD
}

\author{
Recebido: 31/03/2018 - Aprovado:29/6/2018 - Publicado: 30/7/2018 \\ Processo de Avaliação: Double Blind Review
}

\author{
Ana Paula Santana Melo ${ }^{1}$ \\ Mestre em Administração e Desenvolvimento Rural pela Universidade Federal Rural de \\ Pernambuco - UFRPE \\ anapaulasantana22@gmail.com
}

\begin{abstract}
Marcelo da Costa Borba
Doutorando em Agronegócios pela Universidade Federal do Rio Grande do Sul - UFRS marcelodcborba@gmail.com
\end{abstract}

Maria Iraê de Souza Correia

Doutora em Administração pela Universidade Federal Rural de Pernambuco-UFRPE mariairae4@gmail.com

\section{Romilson Marques Cabral}

Doutor em Administração pela Universidade Federal da Bahia Professor do Mestrado em Administração e Desenvolvimento Rural Universidade Federal Rural de Pernambuco e Mestrado Profissional em Administração Pública romilsonmcabral@gmail.com

\begin{abstract}
RESUMO: O objetivo deste artigo é analisar as estratégias desenvolvidas por Organizações Não Governamentais (ONGs) percebidas vias as quatro perspectivas Balanced Scorecard adaptadas à especificidade dessas organizações. Os aspectos metodológicos da pesquisa foram caracterizados pela abordagem qualitativa, com coleta de dados realizada por meio de entrevistas semiestruturadas, análise documental e aplicação de questionário com os líderes e colaboradores. Como técnica de análise dos dados, foi utilizado o método de análise de discurso. Os resultados mostraram que essas organizações já possuem um sistema de controle e acompanhamento das atividades e o cumprimento das normas pela equipe. Também foi percebido como algo em comum nas instituições pesquisadas uma relevante relação a respeito do entendimento das competências essenciais ao comprometimento da equipe com a propagação da missão
\end{abstract}

\footnotetext{
${ }_{1}^{1}$ Autor para correspondência: Universidade Federal Rural de Pernanbuco - UFRPE, Rua Dom Manuel de Medeiros s/n Bloco C -1ㅇandar Dois Irmãos - CEP 52171-900 - Recife- PE, Brasil.
} 
institucional. Por outro lado, há a necessidade de uma ferramenta administrativa para quantificar os resultados, analisar os impactos das ações e a avaliação de desempenho organizacional.

Palavras-chave: estratégia; ferramenta administrativa; desempenho.

ABSTRACT: This paper aims at analyzing the developed strategies by NonGovernmental Organizations (NGOs), which are realized by four Balanced Scorecard perspectives adapted to the specificity of these organizations. The methodological aspects of the research were characterized by the qualitative approach, with data collection through semi-structured interviews, documental analysis and a questionnaire application to leaders and employees. The discourse analysis was used as data analysis technique. The results showed that these organizations already have a system to control and monitor the activities and compliance the norms by the team. It was also realized as something in common in the researched institutions a relevant understanding in terms of the essential competences to the commitment of the team with the institutional mission propagation. On the other hand, there is a need for an administrative tool to quantify the results, to analyze the impacts of the actions and to assess the organizational performance.

Keywords: strategy; administrative tool; performance.

\section{INTRODUÇÃO}

As Organizações Não Governamentais (ONGs) demonstram um crescimento considerável ao longo dos anos, tanto em números de novas instituições quanto em sua participação nos desafios sociais. Essas organizações atuam como elo entre a sociedade e o Estado. Isso faz com que os trabalhos das ONGs ganhem maior importância (TACHIZAWA; POZO; ALVES, 2012). Como resultado da efetividade de trabalhos exercidos por essas organizações, observa-se uma visão institucional diferenciada e a formação de novos padrões no comportamento organizacional. Apesar de se tratar de organizações sem fins lucrativos, não possuem natureza pública, seus aspectos organizacionais singulares exigem ações e qualificação especifica (BASS, 1990).

O planejamento tem sua importância reforçada nas organizações do terceiro setor, visto que o "desempenho dessas organizações precisa ser planejado a partir da missão, tornando-se um elemento fundamental para definição e viabilização dos resultados" (DRUCKER, 1994, p. 80). Os problemas enfrentados por essas organizações estão presentes desde o planejamento até a administração orçamentária e financeira, centrada na diretoria. Na maioria das vezes, a importância do conhecimento 
na área administrativa é percebida apenas quando se precisa responder a uma série de exigências de controles orçamentários feitas pelos órgãos ou instituições com que se relacionam (BEZERRA; ARAÚJO, 2004).

A relevância deste estudo evidencia-se diante da complexidade estrutural das ONGs e da dificuldade encontrada na adaptação das práticas estratégicas de continuidade para perpetuar a missão da organização. Com o crescimento do número de organizações do terceiro setor com objetivos e ideais análogos, acirra-se a concorrência por fontes de recursos. As ONGs apresentam dificuldade em definir suas estratégias de forma clara. Nesse sentido, ao fazer o levantamento dos dados usando as perspectivas do Balanced Scorecard busca-se preencher a lacuna entre uma vaga missão e declarações de estratégia e ações operacionais rotineiras.

\section{DESENVOLVIMENTO}

\subsection{ESTRATÉGIAS NO TERCEIRO SETOR}

A gestão estratégica é um dos principais fatores para a redução de incertezas e de riscos, uma tentativa de previsão do futuro baseada em acontecimentos passados, mas com resultados e análises de indicadores que possibilite identificar oportunidades e ameaças ou a quão competitiva é a organização (CARVALHO; FADUL, 2012). Não diferente, isso também se aplica nas organizações do terceiro setor. Sabe-se que essas organizações possuem particularidades que exigem adaptações das técnicas de gestão de modo a contemplar aspectos essenciais de seu desenvolvimento (SOARES, 2004).

As discussões em relação aos dilemas encontrados em organizações não governamentais, relacionadas à obtenção de recursos para continuar suas atividades organizacionais e prestação de serviços à sociedade, vêm ocupando cada vez mais espaço no campo de estudo sobre continuidade de projetos sociais e da sobrevivência das organizações (SILVA, 2008). Dessa maneira, nota-se que desenvolver recursos próprios é o desafio que tem exigido uma ampla capacidade institucional de inovação e flexibilidade que contribui para o avanço da sustentação das entidades.

A busca pela continuidade no terceiro setor ocorre a partir do momento em que se ambiciona o equilíbrio da utilização dos recursos organizacionais para perpetuar a missão e objetivos da organização, direcionando a gestão para um melhor 
relacionamento com os aspectos internos e externos da instituição e, mostrando uma perspectiva estratégica diferenciada (OLIVEIRA; ROSS; ALTIMEYER, 2005). Dessa forma, Marques (2014) afirma que a complexidade existente na estrutura organizacional dessas instituições reforça a indispensabilidade da utilização de ferramentas de gestão adequadas.

\subsection{INDICADORES DE DESEMPENHO NO TERCEIRO SETOR}

As organizações do terceiro setor estão se deparando com os desafios da atualidade relacionados ao mercado, com isso vêm buscando meios de se adaptarem à realidade em que estão inseridas. Hudson (1999) analisa que quando se trata de organizações orientadas por valores (organizações do terceiro setor) a estratégia é particularmente importante, pois existem acordos entre pessoas com aspirações diferentes que precisam ser integradas para que a organização cresça. Nesse sentido, Coutinho (2010) complementa que a avaliação de resultados no terceiro setor é de extrema relevância, considerando as exigências, como prestar contas tanto ao governo quanto à sociedade, que por meio de doações ou impostos, as financiam. Foi nesse contexto que o Balanced Scorecard surgiu como opção para as instituições do terceiro setor.

Propõe-se que se estabeleçam medidas de eficiência, eficácia e efetividade, ou seja, relacionadas ao desempenho da organização (TENÓRIO, 2003, p.18). Para o autor essas medidas são assim definidas: "Eficiência é a melhor forma de fazer algo com os recursos disponíveis. Eficácia é fazer o que deve ser feito, isto é, cumprir o objetivo determinado. Efetividade é a capacidade de atender às expectativas da sociedade." Ainda sobre tal abordagem, Kaplan e Norton (2004, p.194) evidenciam que "as organizações incapazes de demonstrar melhorias quantificáveis em seu desempenho receberão cada vez menos recursos e não sobreviverão", reafirmando a importância de indicadores de desempenho para a continuidade da organização.

No entanto, Drucker (1997, p. 41) enfatiza que: "quando uma entidade do Terceiro Setor se torna prisioneira da captação de recursos, apresentará problemas sérios e sofrerá sérias crises de identidade". O autor ainda afirma que "a captação de recursos deve ser uma atividade meio ao invés de ser atividade fim, sob pena de a entidade ter sua missão subordinada a essa atividade". Assim, as organizações orientadas por valores 
ficam cada vez mais conscientes do quanto é fundamental monitorar o desempenho organizacional (HUDSON, 1999). Quanto às questões relacionadas aos modelos de gestão, Ferreira (2005) esclarece que esses modelos adotados ultrapassam a análise gerencial de modo simples, sendo preciso considerar o modelo de gestão que revele o predomínio de uma determinada ideologia na base de iniciativas e manutenção dessas instituições.

Desse modo, entende-se que o Balanced Scorecard, quando bem desenvolvido, possibilitará aos gestores das organizações do terceiro setor conduzir e mobilizar esforços e recursos em direção a sua continuidade e eficácia nas ações dos projetos realizados por meio do monitoramento das atividades com a utilização de indicadores (FRAGA; SILVA, 2010).

\subsection{BALANCED SCORECARD EM ORGANIZAÇÕES NÃO GOVERNAMENTAIS}

Devido à natureza complexa da gestão no terceiro setor e à demanda de ferramentas gerenciais, as metas e objetivos almejados possuem focos diferentes, assim não podem ser mensurados apenas com indicadores financeiros, logo torna-se necessária uma metodologia de avaliação mais abrangente que contemple questões qualitativas. Assim, buscando atender a essa necessidade da pesquisa, as estratégias serão analisadas pela perspectiva da ferramenta Balanced Scorecard (BSC).

O Balanced Scorecard surgiu de um estudo patrocinado pelo Instituto Nolan Norton, unidade de pesquisa da KPMG. O estudo intitulado Measuring Performance in the Organization of the Future, objetivou desenvolver um novo modelo de medição de desempenho de empresas. A utilização do Balanced Scorecard (BSC) em organizações não governamentais é uma ampliação de elevada significância para o conceito original, justificando o fato de não restringir a análise dos resultados apenas ao aspecto financeiro, mas considerar o cumprimento de uma determinada missão, no qual a finalidade principal é aumentar a efetividade da comunicação, estabelecida de maneira lógica, com base nas metas estabelecidas, proporcionando aos gestores a recondução dos recursos financeiros e humanos para possibilitar o alcance dessas metas (KAPLAN; NORTON, 1997). 
Dessa forma, entende-se que o BSC permite avaliar o desempenho em dimensões financeiras e não financeiras como "um complemento à medida financeira, suprindo sua deficiência em monitorar ativos intangíveis essenciais para o crescimento futuro" (KAPLAN; NORTON, 1997, p. 68). Os autores afirmam ainda que o líder tem um papel primordial em promover a efetividade da comunicação, pois cabe a ele a responsabilidade os de comunicar as estratégias diretamente à equipe. Segundo os autores, a estrutura básica do Balanced Scorecard, está distribuída na seguinte forma: Perspectiva Financeira; Perspectiva de Clientes; Perspectiva de Processos Internos e Perspectiva do Aprendizado e Conhecimento. De maneira simplificada, no BSC as quatro perspectivas são construídas com base em indicadores internos e externos, de modo que possa orientar a organização a ter uma visão estruturada dos seus objetivos por cada perspectiva, detalhadas no Quadro 3.

Quadro 4 - Principais atributos das perspectivas do Balanced Scorecard:

\begin{tabular}{|c|l|}
\hline PESPECTIVA & \multicolumn{1}{|c|}{ ATRIBUTOS } \\
\hline Financeira & $\begin{array}{l}\text { Medidas financeiras são valiosas para sintetizar as consequências } \\
\text { econômicas imediatas de ações consumadas. Os objetivos financeiros } \\
\text { normalmente estão relacionados à lucratividade. }\end{array}$ \\
\hline Cliente & $\begin{array}{l}\text { Permite que os gestores identifiquem os segmentos de clientes e mercados } \\
\text { nos quais a organização competirá e as medidas de desempenho da } \\
\text { unidade nesses segmentos-alvo. }\end{array}$ \\
\hline Processos internos & $\begin{array}{l}\text { Os executivos identificam os processos internos críticos para o sucesso da } \\
\text { estratégia nos quais a organização deve alcançar a excelência. }\end{array}$ \\
\hline $\begin{array}{c}\text { Aprendizado e } \\
\text { conhecimento }\end{array}$ & $\begin{array}{l}\text { Essa perspectiva identifica a infraestrutura que a organização deve } \\
\text { construir para gerar conhecimento e melhoria a longo prazo }\end{array}$ \\
\hline
\end{tabular}

Fonte: Elaborado pela autora (2016), adaptado de Kaplan e Norton (1997, p.26-29)

A depender da situação da área e estratégia da organização, é possível agregar, se necessário, uma ou mais perspectivas complementares. O desenvolvimento do BSC na organização tem como princípio que a missão e visão institucional estejam bem definidas e concretizadas. A estrutura estabelecida: estratégia, mapa estratégico, objetivos e indicadores procedem das declarações de missão e visão da organização.

O mapa estratégico mostra a relevância do BSC para gestão, pois refere-se a u,ma forma única de lidar com a definição e a disposição das informações que são relevantes para administrar a implementação da estratégia de cada organização, por 
meio do mapa estratégico (SILVA, SILVA, 2015). O Balanced Scorecard preserva as medidas financeiras da continuidade dessas organizações, contudo, acrescenta as medidas de desempenho das outras perspectivas para avaliação de desempenho juntamente à atuação dessas organizações (FRAGA; SILVA, 2010).

Uma organização pode ser motivada por diversos fatores para utilizar o BSC. Para Herrero (2005, p.24) um deles é "quando se percebe que a maioria dos sistemas de mensuração de desempenho na organização está desvinculada da estratégia, e a atenção dos executivos está voltada para o operacional em detrimento da gestão estratégica". Ao se tratar de desempenho, as ONGs têm uma dificuldade histórica para realizar não apenas o monitoramento, mas também, para construir indicadores e para avaliar os resultados, partindo do princípio que o lucro financeiro não funciona como medida, pois essas organizações não possuem finalidades lucrativas (SOUZA; SOUZA, 2011).

O emprego do Balanced Scorecard em organizações do Terceiro Setor, levando em consideração suas peculiaridades e necessidades de adaptação, expressa sua aplicabilidade, visto que a metodologia aplicada contribui para a tradução da estratégia, planejamento e metas a serem executadas, além de facilitar a identificação de fatores críticos organizacionais na avaliação de desempenho e no processo de aprendizagem organizacional (LEBARCKY et al., 2010). Nessa perspectiva, o BSC corresponde a uma ferramenta essencial para avaliar medidas de desempenho nas ONGs, visto que sua criação foi motivada pela insuficiência de medidas de desempenho baseadas apenas em índices contábeis e financeiros.

\section{METODOLOGIA}

Do ponto de vista dos objetivos, esta pesquisa possui caráter exploratório e descritivo. Quanto à abordagem do problema, pode ser classificada como qualitativa. De acordo com os procedimentos técnicos, a pesquisa será classificada como estudo de campo, uma vez que foram realizadas entrevistas e visitas nas organizações que fazem parte da amostra. Quanto à escolha do universo e amostra, buscou-se delimitar às Organizações Não Governamentais filiadas à Associação Brasileira das Organizações não Governamentais ( $\mathrm{ABONG}$ ) que possuam sede no estado de Pernambuco, em função das dificuldades operacionais envolvidas na realização da pesquisa de campo em outras regiões. O universo da pesquisa ficou composto por 28 organizações. A área de atuação 
REMIPE

das ONGs foi utilizada como um dos critérios de escolha da amostra, pois demonstra proximidade com as áreas afins de atuação do programa de pesquisa (administração e desenvolvimento rural). Sendo assim, a amostra foi composta por três instituições. Para serem entrevistados, foram escolhidos um gestor (diretor, gestor ou coordenador) no qual para esse estudo será considerado líder, além de uma pessoa responsável por executar os objetivos organizacionais, que trabalhe próximo a gestão, que será chamado de liderado em cada instituição.

A técnica de coleta de dados atendeu às recomendações relacionadas à pesquisa qualitativa. Foi utilizada a triangulação de dados, que na perspectiva do campo das ciências sociais, corresponde a uma estratégia de pesquisa baseada na utilização de diversos métodos para investigar um mesmo fenômeno (VERGARA, 2004). As diferentes fontes utilizadas para coleta de dados foram: documentos institucionais, entrevistas semiestruturadas com os gestores das ONGs e entrevistas com os colaboradores das ONGs (entrevista semiestruturada foi realizada mediante a utilização de um roteiro, com 26 questões abertas).

$\mathrm{Na}$ análise dos dados foi realizada a interpretação do discurso seguindo a ordem do roteiro. Após a identificação dos postos-chave do discurso, foram comparadas as falas e citações em comum, bem como os pontos divergentes. Logo em seguida, os aspectos encontrados no discurso dos entrevistados foram descritos. Por fim, os dados obtidos foram confrontados com a teoria de aporte e procedeu-se a interpretação das informações, a análise de resultados e a comparação das evidencias empíricas obtidas.

\section{RESULTADOS}

Dentro dos critérios utilizados para seleção da amostra, a entrevista foi aplicada em três Organizações Não Governamentais sediadas na região metropolitana de Recife. As instituições não terão seus nomes divulgados, no entanto, serão apresentadas como: ONG 1 (Áreas Temáticas de Atuação: Agricultura; Meio Ambiente; Economia Solidária; Comunicação; Fortalecimento de outras ONGs/ Movimentos Populares; Segurança Alimentar; Agroecologia), ONG 2 (Áreas Temáticas de Atuação: Meio Ambiente; Fortalecimento de outras ONGs/ Movimentos Populares; Restauração Ambiental; Conservação Ambiental) e ONG 3 (Áreas Temáticas de Atuação: Saúde Meio Ambiente; Relações de gênero; Crianças e Adolescentes; Questão Indígena). 
REMIPE

Sendo assim, este tópico tem como objetivo descrever e analisar as práticas de gestão estratégicas das Organizações Não Governamentais pesquisadas sob as perspectivas do Balanced Scorecard.

\subsection{PRÁTICAS DE GESTÃo ESTRATÉGICA DAS ONGS}

\section{- As estratégias:}

Na ONG 1, existe um plano na organização e. esse é elaborado para um período de 3 anos. A construção do plano tem suporte de consultores externos. Foi salientado pelo líder que o plano se encontra desatualizado, o que pode refletir uma certa ausência de prioridade em relação ao planejamento estratégico $(\mathrm{PE})$ face às atividades rotineiras que tem absorvido a equipe de trabalho. Ficou evidenciado, também, que o plano serve como base para elaboração de projetos e demais atividades. Também tem uma transparência no acesso ao PE por todos os colaboradores. O referido líder informou que a elaboração do planejamento estratégico conta com a participação de todos os interessados na instituição. É realizada uma reunião geral com os territórios (denominação que a ONG 1 utiliza para delimitar as áreas de atuação da instituição), agricultores, coordenadores de projeto, assessoria e coordenação geral no qual leva em consideração a opinião de todos para tomar as principais decisões. A elaboração do planejamento estratégico é decorrente da demanda interna da instituição. Para colaborar na sua elaboração, solicita uma ajuda na condição de parceria com consultores externos.

$\mathrm{Na}$ ONG 2, por sua vez, há desconhecimento sobre a ferramenta de planejamento estratégico, o que indicou que a instituição não possui processo de elaboração de planejamento estratégico, mas possui estratégias que são de acordo com as demandas (estratégia emergente). O que existe é um planejamento operacional anual com a finalidade de consolidar as ações institucionais. O líder demonstrou que possui uma gestão voltada para projetos e uma preocupação em utilizar ferramentas administrativas com a finalidade de otimizar os recursos institucionais. Com o exposto pelo líder da ONG 2, há na organização estratégias de curto prazo que são utilizadas de acordo com as demandas que vão aparecendo. Pode-se considerar que a instituição possui estratégia emergente (aquela ação que surge na organização em resposta a uma oportunidade do ambiente). No caso em análise, a ausência do PE revela uma certa improvisação em relação a um prazo mais largo (planejamento além de um ano). As 
atividades realizadas pela $\mathrm{ONG} 2$, de acordo com o líder, são planejadas em conformidade com os projetos executados.

Já a ONG 3 realiza o planejamento estratégico para um período de 3 a 5 anos, que tem como resultado um plano estratégico em formato de documento no qual toda a equipe tem acesso. O processo de elaboração de PE é realizado em conjunto, com a participação da coordenação, que se reúne com a equipe de trabalho, e com os grupos comunitários (beneficiários) para ouvir suas prioridades e, assim, definir o que é e quais modificações serão necessárias. Conta-se com a ajuda de uma assessoria permanente que realiza uma avaliação do período anterior para assim especificar quais as prioridades futuras, definir quais os problemas que a instituição está enfrentando e fazer uma prospecção das ações que serão executadas nos próximos 3 ou 5 anos.

\section{- Estratégias Financeiras:}

De acordo com o líder da ONG 1, as fontes de recursos institucionais são concentradas em recursos públicos, no entanto, esses recursos que são captados pelas instituições através de diversos órgãos do setor público (governo federal, estadual e outros órgãos) representam entre $80 \%$ a $90 \%$ do recurso total da instituição. A organização ainda tem recurso de cooperação internacional através de projetos com três instituições e, no momento, não possui recursos oriundos de empresas privadas e também não tem interesse em fazer parceria com empresas privadas. Percebe-se, também, uma dificuldade de diálogo com o Estado, mesmo não ocorrendo ruptura dos projetos que estavam em execução, houve redução e atraso dos pagamentos. Esses acontecimentos resultaram na redução de mão de obra que afetou diretamente a qualidade do trabalho realizado pela instituição.

Quando questionado sobre o comportamento dos recursos institucionais nos últimos 5 anos, o líder da ONG 1 afirmou que vários fatores interferiram diretamente no recurso organizacional, dentre eles, pode-se citar a saída da cooperação internacional nos investimentos das ONGs brasileiras. Com isso, o governo passou a ter maior participação na disponibilidade de recursos, pelo menos, na área de agricultura. Inicialmente essa ação foi considerada incomum pois não existia ainda o marco regulatório. Entretanto, as ONGs ampliaram sua participação e passaram a influenciar na formação de políticas, o que proporcionou um avanço nas atividades realizadas. Quanto à facilidade para a captação de recurso, o líder da ONG 1 citou o núcleo de 
mobilização (setor responsável pela captação e mobilização de recursos para a instituição) como uma área estratégica de capacitação de recursos. As ações desse núcleo são todas voltadas apenas para captação de recursos, visto que a organização busca mostrar aos parceiros os resultados de suas ações e, como consequência, tem-se o reconhecimento tanto dos apoiadores quanto dos beneficiários.

Quanto aos obstáculos, foram apontados a restrição dos recursos governamentais, o que dificulta a flexibilização para a ampliação das ações que a instituição quer realizar. Foi citada a escassez de recursos disponíveis para as ONGs e, os poucos editais ofertados, ficam disponíveis por um prazo muito curto, o que dificulta uma elaboração de projeto com a mobilização de todos os envolvidos e da abrangência do financiamento. Por se tratar de organizações que trabalham com bens intangíveis, percebe-se que a área financeira não é prioritária pois essas organizações têm como preocupação principal a realização de suas ações (prestação de serviços para os beneficiários). Mas, entende-se que a gestão dos recursos institucionais é essencial para a viabilização e continuidade das atividades organizacionais.

Ao discorrer sobre a temática financeira, o líder da ONG 2 afirmou que as fontes de recursos são bem diversificadas. O mesmo enfatizou ser arriscado depender apenas de recursos governamentais, assim a instituição buscou ampliar as opções de captação de recursos com parcerias de empresas privadas, organizações não governamentais, cooperação internacional e recurso do núcleo de formação.

De acordo com o líder da ONG 2, o ano de 2016 foi difícil para todas as organizações, mas principalmente para as ONGs. No entanto, a gestão buscou reduzir os gastos, fortalecer a administração, fortalecer a administração de projetos e a equipe incorporou algumas atividades que antes eram terceirizadas. Os recursos captados têm sido necessários para manter as atividades da instituição. Nos anos de 2014-2015, a instituição passou por um bom período financeiro, pois tinha projetos de uma instituição internacional e alguns projetos com o governo. No entanto, houve uma redução do investimento governamental. Tal fator prejudicou muitas ONGs e algumas não tiveram condições de dar continuidade as suas atividades. Pode-se dizer que, no geral, há um equilíbrio dos recursos recebidos e as despesas operacionais nos últimos 5 anos e a organização conseguiu criar o núcleo de formação que fornece formação nas temáticas de meio ambiente. 
A maior facilidade quanto à captação de recursos está associada a uma equipe qualificada e pessoas responsáveis por articular parcerias. No entanto, torna-se necessário induzir demandas de empresas privadas e captar recursos por outras vias, mas a captação deve estar correlacionada com a missão. Os obstáculos referentes à captação de recursos estavam relacionados à gestão dos recursos recebidos e prestação de contas devido às exigências dos financiadores. Todavia, atualmente, o maior obstáculo é sair da rotina das atividades técnicas para buscar novas fontes de recursos.

Conforme o líder da $\mathrm{ONG} \mathrm{3,} \mathrm{as} \mathrm{fontes} \mathrm{de} \mathrm{recursos} \mathrm{são} \mathrm{concentradas.}$ Atualmente, a maior parte dos recursos são oriundos da colaboração internacional. A organização já teve recursos governamentais, mas, hoje em dia, não são solicitados, pois os financiamentos muitas vezes estão interligados às questões que divergem da missão institucional. Os recursos disponibilizados pelos projetos são suficientes para manter o funcionamento da instituição. No entanto, as demandas ainda são maiores do que os recursos disponíveis. Durante os últimos cinco anos (2012-2015), discorreu que os recursos captados pela instituição permaneceram estáveis. A organização busca utilizar apenas os recursos recebidos nos projetos devido à exigência de cooperação internacional, o que de certo modo, possibilitou um equilíbrio entre as receitas e as despesas internas.

\section{- Processos Internos:}

Quanto aos aspectos internos abordados, o líder da ONG 1 esclareceu que as principais atividades realizadas pela instituição são decididas em assembleia, que acontece com a participação do presidente, coordenação, equipe técnica e agricultores. A coordenação colegiada (coordenação colegiada é composta pelo coordenador geral, coordenador técnico-financeiro e coordenador técnico-pedagógico) tem a responsabilidade de organizar os processos internos instituição. As decisões estratégicas são decididas com a diretoria e presidência em assembleia, para depois, passar para as coordenações.

Já o acompanhamento das atividades é realizado pela coordenação. Assim, o monitoramento vai sendo realizado de acordo com o andamento do projeto e, as exigências que vão surgindo com os processos internos são ajustadas. A organização conta com o apoio de consultoria para a avaliação das atividades da organização em todas as áreas institucionais, com a finalidade de contribuir para a melhoria dos 
processos internos. Tal apoio tem contribuído para melhorias das ações mais gerais, organizacionais internas e, também, as ações especificas.

Os processos internos da ONG 2 são organizados pela diretoria de projeto e a diretoria administrativa. A questão da logística das atividades operacionais fica sob a responsabilidade do administrativo. Como a equipe organizacional é considerada pequena, há uma maior troca de informações internas e proporciona uma maior agilidade do funcionamento das atividades. A instituição realiza acompanhamento dos processos internos com a participação da equipe de projeto junto ao administrativo. Desse modo, conta-se com o apoio de uma consultoria prestada por um escritório de contabilidade especializado em Terceiro Setor. Tal consultoria contribui com a orientação de como recolher os tributos, elaboração dos balanços anuais e auxilio na elaboração de contrato para a solicitação de serviço de consultores técnicos internos. $\mathrm{O}$ apoio da consultoria teve sua contribuição refletida até na melhoria do processo gerencial.

Por sua vez, as atividades realizadas dentro da ONG 3 são planejadas no início do ano, mas são reservados de 1 a 3 dias no mês para realizar o monitoramento dos projetos e acompanhar se as atividades estão dentro do prazo, se é necessária alguma modificação, se o recurso é suficiente, entre outros ajustes necessários. Na etapa de execução das atividades internas, o coordenador de projetos fica responsável por definir quais ações serão realizadas e quem irá realiza-las. Após essa etapa, o educador é o responsável por solicitar os recursos necessários para a execução das atividades.

O acompanhamento dos processos internos e a organização das atividades internas são de responsabilidade da equipe da instituição. A instituição ainda tem auditoria externa a cada seis meses por exigência dos financiadores. Tal ação tem como finalidade revisar todos os processos internos institucionais. Esse procedimento faz com que a instituição não precise de apoio de consultoria, além de passar uma certa tranquilidade para a gestão, pois a realização da auditoria permite que a liderança fique focada em ações estratégicas, enquanto seus processos internos são revisados por auditores certificados. 


\subsection{PÚBLICO-ALVO (BENEFICIÁRIOS)}

Na ONG 1, as atividades institucionais são diversificadas. A organização é estruturada em cinco programas que possuem ações, objetivos e metas específicos para cada um. Dentre as diversas atividades realizadas, pode-se citar cursos, oficinas, intercâmbio e assessoria técnica. As quantidades de ações junto à comunidade são relativas, pois dependem do financiamento dos projetos, mas as atividades podem ser intensificadas em um período e reduzidas em outro. Houve uma ampliação no serviço prestado à comunidade de beneficiários. Esse aumento foi percebido tanto em sua diversidade quanto em sua qualidade. A instituição busca dar continuidade em suas ações mesmo com a finalização dos projetos através de assessoria continuada. A comunidade de beneficiários demonstra reconhecimento através da busca pelas ações desenvolvidas pela organização. Assim, a instituição busca construir uma relação de confiança com o público beneficiário para que a relação seja com a organização, pois assim, as atividades podem ser executadas independente de quem seja responsável por sua realização.

Conforme a ONG 2, a instituição realiza diversos projetos junto a diversos atores sociais, o que de certa forma, possibilita a realização de diversas atividades. Também foi declarado que em relação à qualidade do trabalho realizado pela organização houve uma melhora significante, demonstrada pelo reconhecimento de diferentes atores sociais. Como exemplo, foi mencionado a oportunidade de coordenar uma política pública, convites para participar de reuniões em grupos de trabalhos em universidade, participação na esfera pública e conselho de gestor de unidade de conservação, em reuniões setoriais. O reconhecimento também é notado pelos financiadores, recebimento de convites para participação em eventos e indicações para prestação de serviços. Referente aos cursos de capacitação, nota-se o retorno para participar de novos cursos. As avaliações realizadas no final dos cursos de capacitação também possibilitam ter feedbacks positivos das ações prestadas.

Já a ONG 3 declarou que as atividades são diversificadas, visto que os projetos realizados pela instituição são direcionados a ações diferentes para públicos variados. Algumas vezes, é necessário que as atividades sejam concentradas em poucas ações para assim serem inseridas nos projetos, devido à redução de recursos destinados à execução dos projetos. Referente aos serviços prestados pela instituição, houve melhora 
principalmente em sua qualidade, pois a organização busca fazê-lo de maneira mais organizada e qualificada. O mesmo declarou ainda que a comunidade demonstra reconhecimento pelas atividades desempenhadas pela organização, pois existe um interessante para que a instituição continue com suas ações. A instituição busca acompanhar e avaliar a melhoria tanto da qualidade quanto da quantidade dos serviços prestados aos beneficiários através de indicadores de ações e impactos da instituição. Os beneficiários demonstram reconhecimento pela procura das ações realizadas, através de comentários, elogios e respostas dos resultados dos projetos.

\subsection{APRENDIZADO E CONHECIMENTO}

A ONG 1 busca fomentar o aprendizado e crescimento dos funcionários, também, procura incluir nos projetos ações de capacitação e formação interna e inserir na submissão de novos projetos ações referentes à formação de equipe. Buscando estimular o aprendizado e crescimento dos funcionários, flexibiliza o horário de trabalho para a realização de especializações e formações. A instituição possui, ainda, momentos para compartilhar informações, em que um técnico que conhece mais sobre alguma especificidade divide esse conhecimento com toda a equipe. Também existe o incentivo à participação da equipe em seminários, congressos, cursos e publicação de artigos acadêmicos. Atualmente, a organização não possui um programa de treinamento. Mas é pretendido na elaboração do novo planejamento estratégico, incluir ações para a elaboração de um programa de treinamento com uma abordagem que inclua algumas temáticas de interesse para a equipe.

Com relação à ONG 2, são incentivados o aprendizado e o crescimento através do fomento à capacitação, custeio de cursos e flexibilização de atividades. O conhecimento e a informação são tratados como algo intrínseco da instituição. A instituição disponibiliza o conteúdo de pesquisa, flexibiliza o horário de trabalho e metas e ainda custeia cursos e viagens. Atualmente, não tem um programa de treinamento e cursos formalizado na instituição. A organização busca corresponder ao aprendizado permitindo que o funcionário seja protagonista na área de formação e indicando para atuação na área de formação. A instituição incentiva o aprendizado e busca disseminar o conhecimento na equipe através de seminários. No momento, a ONG não possui programa de treinamentos e cursos. 
Já a ONG 3 busca incentivar o aprendizado e o crescimento dos funcionários na medida do possível. No momento, a instituição não possui um programa de treinamento. O reconhecimento não é pelo aprendizado. Diferente das métricas tradicionais de desempenho organizacional, avaliar a estratégia institucional sob as perspectivas do Balanced Scorecard proporciona a definição e a comunicação das prioridades para todos que fazem parte da instituição. Dessa forma, os processos gerenciais que abrangem as perspectivas incorporadas pelo Balanced Scorecard podem assegurar que a organização esteja alinhada e focalizada com a implementação da estratégia de longo prazo (KAPLAN ; NORTON, 1997).

\section{CONSIDERAÇÕES FINAIS}

Como resultado na análise das práticas de gestão estratégicas, a ONG 1 apresentou um conhecimento amplo sobre gestão e planejamento estratégico. Tal conhecimento é traduzido para a instituição de modo claro e objetivo. Foram realizadas algumas críticas aos modos de gestão tradicional e esclarecida a necessidade de adaptação de algumas ferramentas administrativas para quantificar os resultados, analisar os impactos das ações e avaliação de desempenho organizacional. A instituição apresentou práticas de gestão que abrangem todas as áreas presentes nas perceptivas do Balanced Scorecard.

Sobre esse aspecto, a ONG 2 relatou que não realiza processo de planejamento estratégico, no entanto, a instituição possui estratégias emergentes que são aplicadas de acordo com as demandas decorrentes. Existe uma preocupação em acompanhar as ações organizacionais. Para isso, realizam-se reuniões periódicas e utilizam-se ferramentas administrativas de gestão de projetos para acompanhar e avaliar os projetos em execução. Dentre as perceptivas do $B S C$, apenas a que se refere ao aprendizado e conhecimento não é realizada de modo sistematizado e formal.

Por sua vez, a ONG 3 explicitou que as práticas de gestão estratégica são realizadas por demanda dos financiadores. Busca-se alinhar os processos internos de acordo com o que é solicitado nas auditorias, pois existe uma exigência de controle e transparência tanto nas ações quanto no uso dos recursos. Dentre as categorias do BSC, a do aprendizado e conhecimento foi a que menos tem ações, no entanto, a instituição justificou não ter recursos, no momento, para formalizar as ações nessa área. 
Como sugestão para pesquisas futuras, recomenda-se um maior aprofundamento da temática abordada, ou até uma seleção mais ampla de ONGs, com a aplicação desta investigação adotando uma abordagem de natureza quantitativa, com a finalidade de categorizar os aspectos referentes às práticas de gestão estratégica em organizações não governamentais.

\section{REFERÊNCIAS}

CARVALHO, F. Práticas de planejamento estratégico e sua aplicação em organizações do terceiro setor. São Paulo: Universidade de São Paulo - USP, 2004.

CARVAlHO, A. O. DE; FADUL, E. M. C. Os Fatores Críticos de Sucesso na Gestão de Organizações Não Governamentais. Administração Pública e Gestão Social -PGS, v. 4, n. 2, p. 148-171, 2012.

COUTINHO, N. DE A. O Balanced Scorecard Aplicado às Organizações NãoGovernamentais: Um Modelo Aplicável a uma Organização do Terceiro Sector. Porto: Universidade do Porto, 2010.

FERREIRA, V. C. P. ONGs NO BRASIL: Um Estudo Sobre suas Características e Fatores que têm Induzido Seu Crescimento. Rio de Janeiro: Fundação Getúlio Vargas, 2005.

FISCHER, R. M. O desafio da colaboração: práticas de responsabilidade social entre empresas e terceiro setor. São Paulo: Editora Gente, 2002.

FRAGA, R. V.; SILVA, C. E. Balanced Scorecard: planejamento estratégico no contexto das organizações do Terceiro Setor. Revista Brasileira de Administração Científica, v. 1, n. 1, p. 5-31, 2010.

HERRERO, E. Balanced Scorecard e a Gestão Estratégica: Uma Abordagem Prática. $3^{\mathrm{a}}$ ed. Rio de Janeiro: Editora Elsevier, 2005.

HUDSON, M. Administrando Organizações do Terceiro Setor : o desafio de administrar sem receita. São Paulo: Editora Makron Books, 1999.

KAPLAN, R. S.; NORTON, D. P. Estrategia em ação: Balanced Scorecard. 6. ed. Rio de Janeiro: Campus, 1997a.

A Estratégia em Ação: Balanced Scorecard. 1 ${ }^{\text {a }}$ ed. Rio de Janeiro: Editora Campus Ltda, $1997 b$.

LEBARCKY, F. DA V. et al. O Balanced Scorecard como Ferramenta de Avaliação de Desempenho Organizacional no Terceiro Setor. VII Congresso USP de Controladoria e Contabilidade. Anais...São Paulo-SP: 2010 
MARQUES, S. R. C. A Importância da Gestão na Sustentabilidade de Organizações Sem Fins Lucrativos Prestadoras de Serviços Sociais. Coimbra: Universidade de Coimbra, 2014.

MINTZBERG, $\mathrm{H}$. et al. O processo da estratégia - conceitos, contextos e casos selecionados. $4^{\circ}$ edição ed. Porto Alegre: Editora Bookman, 2007. v. 29

OLIVEIRA, B.; ROSS, E. S.; ALTIMEYER, H. Y. Proposta de um modelo de planejamento estratégico para instituições sem fins lucrativos. Revista da FAE, v. 8, n. 1, p. 69-80, 2005.

OLIVEIRA, W. A. DE. Terceiro Setor e o Desafio da Sustentabilidade : Estudo Salvador-Bahia-Brasil. Coimbra: Universidade de Coimbra, 2011.

SILVA, L. C. E; SILVA, D. M. Balanced Scorecard no Terceiro Setor: Uma Aplicação Prática. PhD Proposal, v. 1, 2015.

SILVA, F. M. DA. Terceiro Setor e O Desafio da Sustentabilidade : aspectos políticos , técnicos, econômicos e sociais. Porto Alegre: Universidade Federal do Rio Grande do Sul, 2008.

SOARES, C. A. L. Gestão Estratégica e Liderança no Terceiro Sector: Um Estudo de Caso. Niterói: Universidade Federal Fluminense, 2004.

SOUZA, F. A.; SOUZA, B. C. Análise de Desempenho em ONGs: propondo um modelo adaptado. RESAC - Revista Sociedade, Administração e Contemporaneidade, v. 1, p. 21-32, 2011.

TACHIZAWA, T. Organizações não Governamentais e Terceiro Setor. São Paulo: Atlas, 2002.

TENÓRIO, F. G. Gestão de ONG: principais funções gerenciais. 9. ed. Rio de Janeiro: Editora FGV, 2003.

VOLTOLINI, R. (Org.). Terceiro Setor: Planejamento \& Gestão. São Paulo: Senac São Paulo, 2004. 